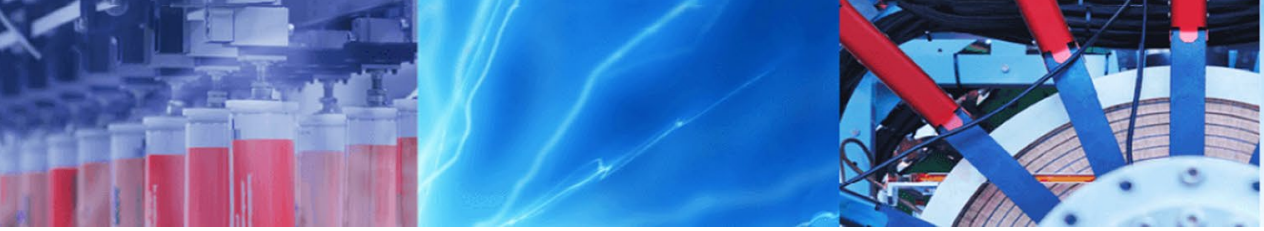

Research Article

\title{
Sol-gel synthesis of polyacrylamide-stannic arsenate nanocomposite ion exchanger: binary separations and enhanced photo-catalytic activity
}

\author{
Ajay Kumar ${ }^{1} \cdot$ Gaurav Sharma $^{2} \cdot$ Manita Thakur $^{3} \cdot$ Deepak Pathania $^{4}$
}

(C) Springer Nature Switzerland AG 2019

\begin{abstract}
In this, polyacrylamide-stannic arsenate nanocomposite (PA/SANC) ion exchanger has been synthesized using sol-gel technique. Different instrumental techniques were employed to characterize the PA/SANC. XRD results illustrate semicrystalline nature of material. TEM images confirmed that the size of PA/SANC was in nano-range. Nanocomposite have superior physicochemical properties including ion exchange capacity, elution behavior, effect of eluent concentration, distribution coefficient $\left(K_{d}\right)$, effect of temperature and $\mathrm{pH}$ study. PA/SANC have $0.92 \mathrm{meq} / \mathrm{g}$ value of ion exchange capacity as compared to inorganic part $(0.39 \mathrm{meq} / \mathrm{g})$. On the basis of $\mathrm{K}_{\mathrm{d}}$ values, it has been found that nanocomposite was highly selective for $\mathrm{Mg}(\mathrm{II})$ ions $\left(\mathrm{K}_{\mathrm{d}}=222.90\right)$. PA/SANC was also explored for binary separation of different metal pairs. PA/SANC degraded $86.22 \%$ of sunset yellow under $3 \mathrm{~h}$ of solar exposure.
\end{abstract}

Keywords Nanocomposite $\cdot$ Polyacrylamide $\cdot$ Stannic arsenate $\cdot$ Heavy metals $\cdot$ Sunset yellow

\section{Introduction}

In present phase, the evolution of new manufacturing processes results severe damage to plants, human and wildlife. Different human activities including agricultural runoff with excess fertilizers, pesticides, industrial effluents, construction sites and manure liquid continuously polluted our water sources [1-3]. Untreated effluent is the most important cause for the degradation of water sources and environment. These unwanted materials impart poor health effects such astyphoid, cholera, smallpox, tuberculosis etc. It also affects the urbane area which causes loss of crop productivity. The industrial waste includes venomous contaminants such as dyes, phenols, pesticides, heavy metals etc $[4,5]$.

The presence of heavy metals raises serious threats and diseases to all over the biosphere. Different heavy metals lead, aluminium, copper, cadmium, zinc, chromium, nickel, arsenic, manganese and mercury impart different poisonous effects to human health. These are produced in textile industry, incineration of metals, fungicides, insecticides, leather tanning industry, metallurgical industries, mining, automobile emissions, refining of heavy metals, cement and asbestos industries etc. The long-time exposure of heavy metals causes breathing problems, throat and lung irritation, stomach pain, gastrointestinal dysfunction, carcinogenic, endocrine disruptor, mutagenic, lung damage and cancer [6-12].

Also, dyes are the major component of textile industries and present in effluent streams which symbolize adversarial effects on human and marine life $[13,14]$. The ingestion of some coloured compounds can impart adverse health effects including kidneys and liver damage, anemia, abdominal pain, hypertension, neurological problem etc.

$\triangle$ Manita Thakur, manitathakur1989@gmail.com | 'Department of Chemistry, IEC University, Baddi, Himachal Pradesh 174103, India. ${ }^{2}$ School of Chemistry, Shoolini University, Solan, Himachal Pradesh 173212, India. ${ }^{3}$ Department of Chemistry, Maharishi Markandeshwar University, Solan, Himachal Pradesh 173212, India. ${ }^{4}$ Department of Environmental Sciences, Central University of Jammu, Bagla (Rahya-Suchani), Distt. Samba, Jammu \& Kashmir 181143, India. 
Both heavy metals and dyes are non-biodegradable, poisonous, carcinogenic and mutagenic in nature. Therefore, these pollutants should be expelled from water sources [15-18].

There are numerous methods such as osmosis, filtration, reverse osmosis, membrane filtration, photocatalysis, adsorption and ion exchange has been used to treat contaminated water. Recently Budnyak et al. [19], has studied various parameters for the sorption of $M B$ dye and Uranium( $\mathrm{VI})$ ions by using lignin and mesoporous silca based hybrid material and they got outstanding results for the removal of dye. [19, 20].

lon exchange process is widely used for wastewater treatment due to its low cost. There are two different forms of ion exchangers such as inorganic and organic ion exchangers [21-24]. Both ion exchangers possess some drawbacks like unstable at elevated temperature and radiations, expensive and impotent to accomplish huge volume of waste discharges. Therefore, to subjugate the limitations of organic and inorganic ion exchangers, composite ion exchangers have been introduced. The composite ion exchangers were synthesized by incorporating organic material into the inorganic part. These materials show exceptional behavior including chemical, mechanical and thermal strength [25-30].

Organic polymers such as polyaniline, pectin, cellulose, polystyrene, starch, gelatin, alginate, polyacrylamide etc. provide extensive number of exchangeable donor sites with large exterior area. Polyacrylamide is a polymer has superior water absorbent property and form gel when mixed with water. It is explored in gel electrophoresis, contact lenses, thickener and suspending agent. It is nontoxic, soil conditioner and used in water treatment industry [31].

Sunset yellow (SY) is a orange azo dye with molar mass of $452.36 \mathrm{~g} \mathrm{~mol}^{-1}$. Its chemical formula is $\mathrm{C}_{16} \mathrm{H}_{10} \mathrm{~N}_{2} \mathrm{Na}_{2} \mathrm{O}_{7} \mathrm{~S}_{2}$ and IUPAC name is disodium 6-hydroxy-5-[(4-sulfophenyl) azo]-2-naphthalenesulfonate. It is found from petroleum based aromatic hydrocarbons. SY is used as food colouring agent in deserts, sauces, candy, snacks, puddings and sweets, jams, preserved foods and in cosmetics. Exposure of SY is highly carcinogenic and causes allergic reactions such as urticaria, swollen skin, headache, watery eyes, numbness, asthma, cough and sinus attacks [32].

These materials have wide applicability in various regions including chemical separation, water treatment, catalyst, antimicrobial activity, fuel cell and sensing. In recent years, composite materials on nanoscale has been explored on large scale due to their multifunctionality, specificity and selectivity in different fields [33-36]. An excellent study has been concluded by Kołodyńska et al. [37], on organic-inorganic hybrid materials for heavy metal removal. They summarizes various synthesis strategies and removal of various heavy metal [37]. The present study includes the synthesis of polyacrylamidestannic arsenate nanocomposite (PA/SANC) nanocomposite ion exchanger. Different physicochemical properties of nanocomposite were studied. PA/SANC was characterized using SEM, FTIR, TEM, XRD and EDX. On the basis of distribution studies, nanocomposite was explored for the exclusion of $\mathrm{Mg}^{2+}$ and binary separations of metal ions were also attained on column. PA/SANC was explored for the photocatalytic degradation of sunset yellow (SY).

\section{Experimental}

\subsection{Reagents and instruments}

The reagents employed in this work were stannous chloride $\left(\mathrm{SnCl}_{2} \cdot 2 \mathrm{H}_{2} \mathrm{O}\right)$ sodium arsenate $\left(\mathrm{Na}_{2} \mathrm{HAsO}_{4} \cdot 7 \mathrm{H}_{2} \mathrm{O}\right)$, acryl amide $\left(\mathrm{C}_{3} \mathrm{H}_{5} \mathrm{NO}\right)$, sodium chloride $(\mathrm{NaCl})$, sodium hydroxide $(\mathrm{NaOH})$ and nitric acid $\left(\mathrm{HNO}_{3}\right)$ procured from CDH Pvt. Ltd., India. Stock solutions were prepared by mixing suitable amounts of salts in double distilled water. The main instruments used were SEM (scanning electron microscope), TEM (transmission electron microscope), FTIR (Fourier transform infrared) spectrometer, XRD (X-ray diffraction), EDX (energy dispersive $X$-ray analysis), magnetic stirrer and digital electronic balance.

\subsection{Preparation of stannic arsenate (SA)}

Stannic arsenate (SA) was prepared by mixing $0.2 \mathrm{M}$ stannous chloride and $0.4 \mathrm{M}$ sodium arsenate drop-wise in definite proportion of 2:1 with constant stirring at temp. $60{ }^{\circ} \mathrm{C}$. The $\mathrm{pH}$ of above mixture was set aside between 0 and 1 by adding $0.1 \mathrm{~N} \mathrm{HNO}_{3}$. The subsequent mixture was taken aback for $2 \mathrm{~h}$ uninterruptedly. Then the obtained precipitates were filtered, washed thoroughly with double distilled water and dried at $60^{\circ} \mathrm{C}$ in oven for $24 \mathrm{~h}$ [38].

\subsection{Synthesis of polyacrylamide-stannic arsenate nanocomposite (PA/SANC) ion exchanger}

PA/SANC ion exchanger was synthesized in two phases $[38,39]$. In first, $0.2 \mathrm{M}$ stannous chloride and $0.4 \mathrm{M}$ sodium arsenate (2:1) were mixed with constant stirring at room temperature. The $\mathrm{pH}$ of resulting mixture was adjusted to $0-1$ by adding $0.1 \mathrm{~N}$ nitric acid. In the second step, the $1.8 \mathrm{M}$ acryl amide was dissolved in double distilled water and solution of thick consistency was obtained. Now pour the slurry of acrylamide in the mixture of stannous chloride and sodium arsenate. The resultant mixture was stirred for 2-3 $\mathrm{h}$ and kept for digestion with intermittent shaking. Then to eradicate the contaminations, the 
precipitates were filtered and washed with double distilled water a number of times. The precipitates of PA/SANC thus obtained were dried at $60^{\circ} \mathrm{C}$ in a hot air oven. The desiccated precipitates were transformed into $\mathrm{H}^{+}$by adding in $0.1 \mathrm{~N} \mathrm{HNO}_{3}$ solution for $24 \mathrm{~h}$ with occasional shaking. Then the precipitates were filtered and washed with distilled water to take out the remaining acid. In this way, different samples of PA/SANC ion exchanger were synthesized and the sample with highest IEC value was explored for further detail study.

\subsection{Physicochemical properties}

\subsection{1 lon exchange capacity (IEC)}

To determine the IEC, $1.0 \mathrm{~g}$ of PA/SANC in $\mathrm{H}^{+}$form was taken in glass column and glass wool was fitted at the end of column. For the complete elution of $\mathrm{H}^{+}$ions, $1 \mathrm{M}$ sodium nitrate was used at flow rate of $0.5 \mathrm{~mL}$ per min. The collected effluent was titrated with standard solution of $0.1 \mathrm{M}$ sodium hydroxide using phenolphthalein as indicator. The IEC was calculated using the formula as reported in literature [40].

\subsubsection{Effect of eluent concentration}

In this, fixed volume of $\mathrm{NaNO}_{3}$ with different concentration i.e. $0.2 \mathrm{M}, 0.4 \mathrm{M}, 0.6 \mathrm{M}, 0.8 \mathrm{M}, 1.0 \mathrm{M}, 1.2 \mathrm{M}, 1.4 \mathrm{M}$ and $1.6 \mathrm{M}$ was passed through a column containing $1.0 \mathrm{~g}$ of nanocomposite. The flow rate of the eluent was adjusted to $0.5 \mathrm{~mL}$ per minute. The collected eluent was titrated against $0.1 \mathrm{M}$ sodium hydroxide using phenolphthalein as indicator to determine the $\mathrm{H}^{+}$ions eluted out from the column [40].

\subsubsection{Elution behaviour}

In this method, sodium nitrate solution of optimum concentration was passed through the column with $1.0 \mathrm{~g}$ of $\mathrm{PA} / \mathrm{SANC}$ for complete elution of $\mathrm{H}^{+}$ions. The effluent was cumulated in $10.0 \mathrm{~mL}$ fraction at a flow rate of $0.5 \mathrm{~mL}$ per minute and titrated against $0.1 \mathrm{M}$ sodium hydroxide using phenolphthalein as an indicator [40].

\subsubsection{Thermal studies}

The effect of thermal treatment on ion exchange capacity of PA/SANC was also studied. In this, $1.0 \mathrm{~g}$ of PA/SANC (in $\mathrm{H}^{+}$form) was heated at different temperatures ranged from 100 to $600^{\circ} \mathrm{C}$ in muffle furnace for $1 \mathrm{~h}$. Weight and color of PA/SANC were observed after cooling at room temperature and IEC was calculated using standard column process [40].

\subsection{5 pH titration study}

In this, $0.5 \mathrm{~g}$ of the PA/SANC (in $\mathrm{H}^{+}$form) were settled in $250 \mathrm{~mL}$ flasks containing equimolar solution of alkali metal chloride and their hydroxide in different volume ratio. The volume was kept constant at $50 \mathrm{~mL}$ and $\mathrm{pH}$ of each solution was observed after $24 \mathrm{~h}$ at room temperature till the equilibrium attained [40].

\subsubsection{Distribution coefficient studies $\left(\mathrm{K}_{d}\right)$}

The distribution coefficient of different metal ions i.e. $\mathrm{Ni}^{2+}$, $\mathrm{Co}^{2+}, \mathrm{Cd}^{2+}, \mathrm{Zn}^{2+}, \mathrm{Cu}^{2+}, \mathrm{Mg}^{2+}, \mathrm{Pb}^{2+}, \mathrm{Al}^{3+}$ was calculated using batch method. $0.2 \mathrm{~g}$ of PA/SANC (in $\mathrm{H}^{+}$form) was put in $20 \mathrm{~mL}$ of different metal nitrates solution and kept for $24 \mathrm{~h}$ with continuous shaking at $25 \pm 2^{\circ} \mathrm{C}$. Then, the metal ions in the solution before and after equilibrium were determined by titrating against standard $0.01 \mathrm{M}$ solution of EDTA. The $K_{d}$ values were calculated using the formula as given in literature [41].

\subsection{Quantitative separation of metal ions from synthetic binary mixtures}

The quantitative separations of different metal ions were achieved onto PA/SANC column. The mixture of two different metal ions each with preliminary concentration of $0.1 \mathrm{M}$ were loaded onto PA/SANC column and passed at a flow rate of $0.2 \mathrm{~mL} / \mathrm{min}$. The mixture of metal ions was disseminated two or three times to make sure the complete absorption of metal ions on PA/SANC. The adsorbed metal ions were eluted with suitable solvent of required concentration. The effluent was collected in $10 \mathrm{~mL}$ fraction at a flow rate of $0.2 \mathrm{~mL}$ per minute and titrated beside $0.01 \mathrm{M}$ disodium salt of EDTA using different indicators such as PAN (1-(2-Pyridylazo)-2-naphthol) and EBT (Eriochrome Black T) $[41,42]$.

\subsection{Photocatalytic activity}

Photo-catalytic activity of PA/SANC was observed by the degradation of sunset yellow (SY). The initial concentration of dye was taken $1 \times 10^{-5} \mathrm{M}$ and $100 \mathrm{mg}$ of the PA/SANC was added to form slurry. The slurry was placed in dark for $1 \mathrm{~h}$ to form adsorption desorption equilibrium and the slurry was bare to sunlight precisely. The effect of photocatalysis of PA/ SANC was studied at different time intervals. The concentration of dye was determined by UV-visible spectrometer at $480 \mathrm{~nm}$ wavelength $[43,44]$. The percentage degradation of SY was calculated by the formula as given

$\%$ Degradation $=\frac{C_{o}-C_{t}}{C_{o}} \times 100$ 
Table 1 Conditions for the preparation of various samples of PA/ SANC

\begin{tabular}{llllll}
\hline $\begin{array}{l}\text { Sample } \\
\text { no. }\end{array}$ & A (mol/L) & $B(\mathrm{~mol} / \mathrm{L})$ & $\mathrm{C}(\mathrm{mol} / \mathrm{L})$ & $\begin{array}{l}\mathrm{IEC} \\
\text { (mequiv/g) }\end{array}$ & Yield $(\mathrm{g})$ \\
\hline S-1 & 2 & 1 & - & 0.39 & 1.0 \\
S-2 & 2 & 1 & 0.4 & 0.15 & 1.0 \\
S-3 & 2 & 1 & 0.8 & 0.45 & 1.0 \\
S-4 & 2 & 1 & 1.1 & 0.18 & 1.3 \\
S-5 & 2 & 1 & 1.4 & 0.09 & 1.6 \\
S-6 & 2 & 1 & 1.8 & 0.92 & 1.8 \\
S-7 & 2 & 1 & 2.0 & 0.63 & 1.8 \\
\hline
\end{tabular}

A: Stannic chloride, B: Sodium arsenate, C: Acrylamide

Where $C_{o}$ and $C_{t}$ are initial and final concentration of dye at time $\mathrm{t}=0$ and $\mathrm{t}=\mathrm{t}$ respectively.

The band gap of PA/SANC was obtained by tauc relation as given

$\alpha h v=\mathrm{B}\left(\mathrm{h} \nu-\mathrm{E}_{\mathrm{g}}\right)^{\mathrm{n}}$
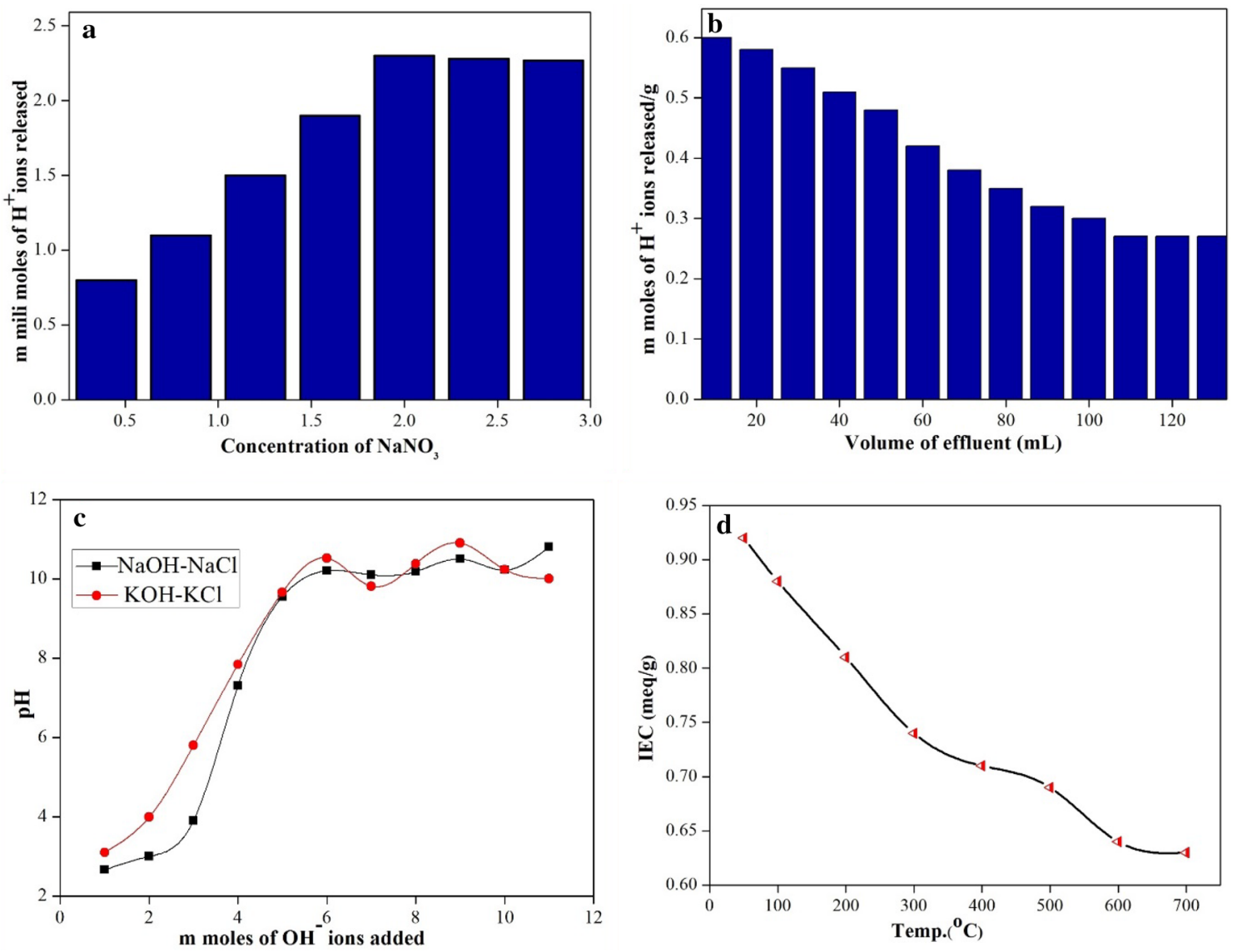

where $\alpha$ is absorption coefficient $=2.303 \mathrm{~A} / \mathrm{l}, \mathrm{E}_{\mathrm{g}}=$ optical band gap, $\mathrm{B}=$ band tailing parameter, hv= photon energy, $n=1 / 2$ for direct band gap.

\section{Results and discussion}

Seven different samples of PA/SANC ion exchanger were prepared by varying the amount of acrylamide as shown in Table 1. Sample S-6 has maximum value of ion exchange capacity i.e. 0.92 mequiv/g at $1.8 \mathrm{M}$ concentration and explored for further studies. PA/SANC have enhanced ion exchange capacity ( 0.92 mequiv/g) as compared to its inorganic counterpart ( 0.39 mequiv/g). Higher ion exchange capacity of PA/SANC was due to incorporation of acrylamide with stannic arsenate which accommodate the large surface area for the accretion of numerous multiple donor sites [40].

Effect of eluent concentration illustrates that value of IEC varies with the concentration of eluent as depicted in Fig. 1a. The highest IEC was found at $2.4 \mathrm{M}$ sodium nitrate

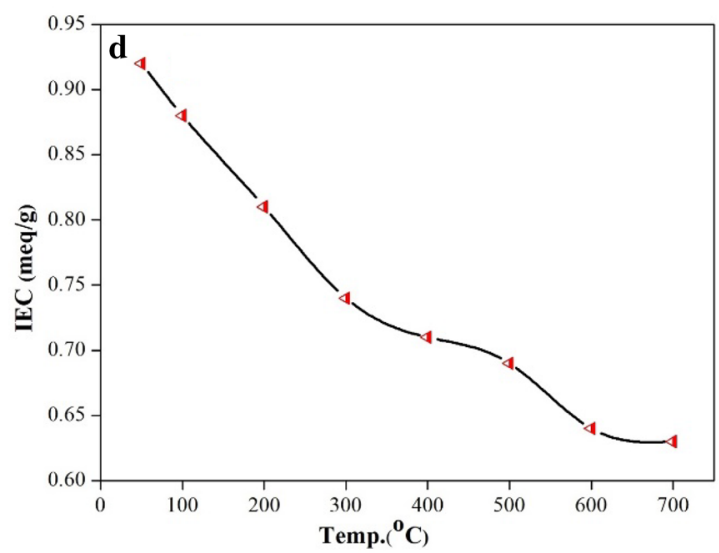

Fig. 1 a Effect of eluent concentration on ion exchange capacity of PA/SANC, $\mathbf{b}$ elution behavior of PA/SANC, $\mathbf{c}$ pH-titration curves of PA/ SANC, $\mathbf{d}$ Effect of temp. on IEC of PA/SANC 

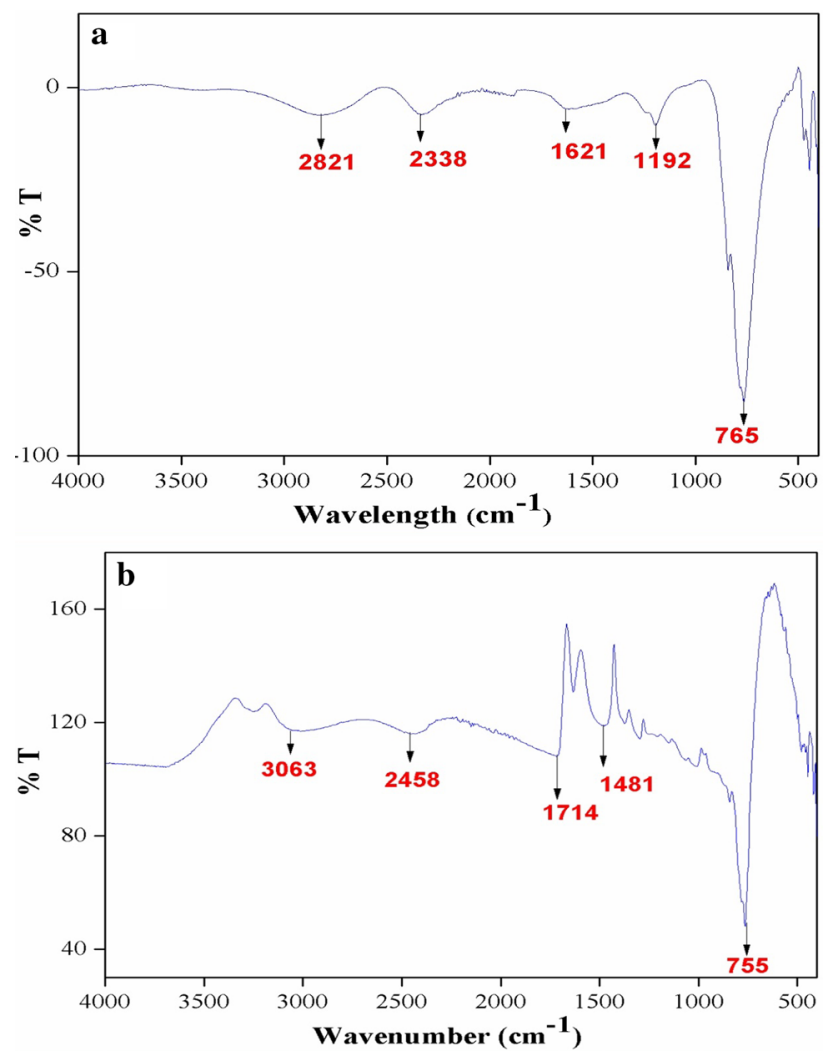

Fig. 2 FTIR spectra of a SA and b PA/SANC ion exchanger as a result of complete discharge of $\mathrm{H}^{+}$ions from PA/SANC column. Subsequently, above this concentration of eluent, IEC becomes almost constant.

Elution behavior for the complete elution of $\mathrm{H}^{+}$ions from PA/SANC column was illustrated in Fig. 1b. It has been observed that the enhanced elution ratio for PA/SANC was very fast primarily, $130 \mathrm{~mL}$ of $1 \mathrm{M}$ sodium nitrate solution was required for complete elution of $\mathrm{H}^{+}$ions from PA/ SANC column. The rate of ion exchange is faster initially and decreases gradually because there were more $^{+}$ions for exchange in beginning.

The $\mathrm{pH}$ titration studies of PA/SANC showed the bifunctional character of the synthesized material as shown in Fig. 1c. It has been noticed that the synthesized material was indicated as cation exchanger at low $\mathrm{pH}$ when no amount of $\mathrm{OH}^{-}$ions added. Hence, it was concluded that at low $\mathrm{pH}$, the weak acidic groups were un-dissociated. Further, the addition of sodium hydroxide resulting the above solution to be neutralized with the completion of ion exchange process. Initially, there was continuing escalation in the titration curve with increased value of $\mathrm{pH}$ and sudden rise found at the end due to complete exchange of $\mathrm{Na}^{+}$and $\mathrm{K}^{+}$ions [45]. The exchange rate of ions was noticed fast for $\mathrm{H}^{+}-\mathrm{K}^{+}$system in contrast to $\mathrm{H}^{+}-\mathrm{Na}^{+}$system.

Figure $1 \mathrm{~d}$ shows the effect of temperature up to $700^{\circ} \mathrm{C}$ on IEC of PA/SANC. It has been observed that as temperature rises, there was decrease in IEC because organic part of PA/SANC get decomposed.
Fig. 3 Scanning electron micrographs a, b SA, c, d PA/ SANC ion exchanger

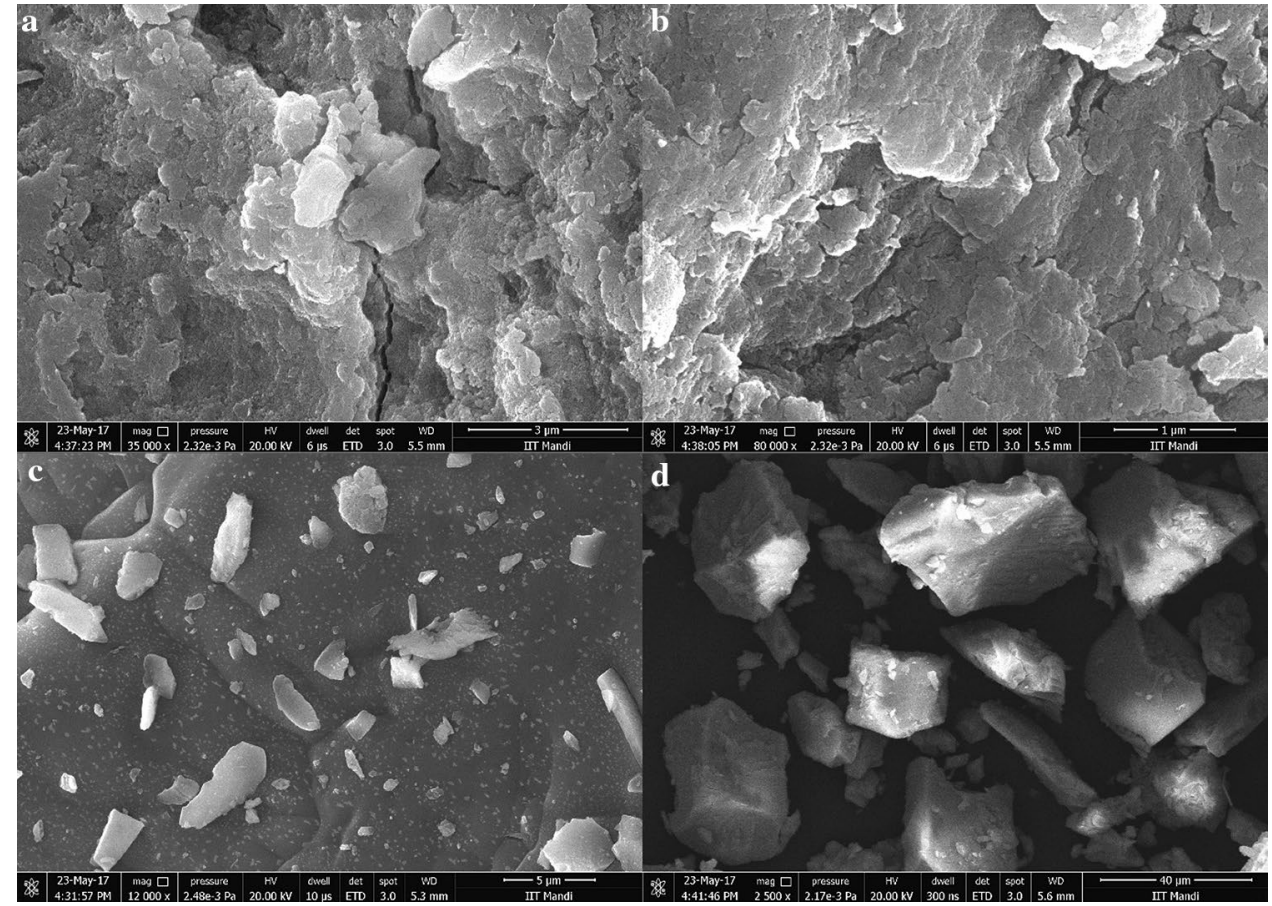

SN Applied Sciences A SPRINGER NATURE journa 


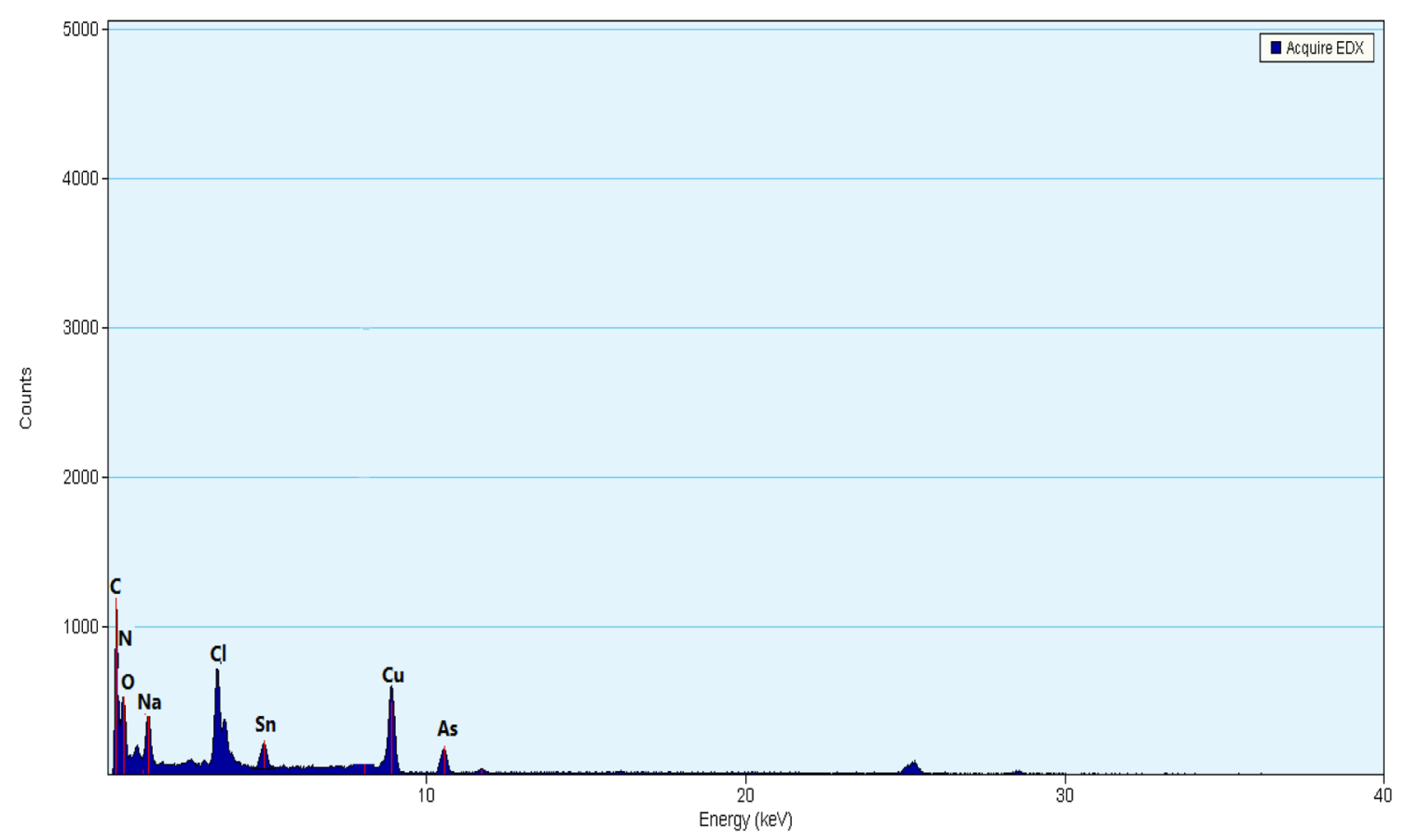

Fig. 4 Energy dispersive X-ray graph of PA/SANC

Fig. 5 Transmission electron micrograph of PA/SANC
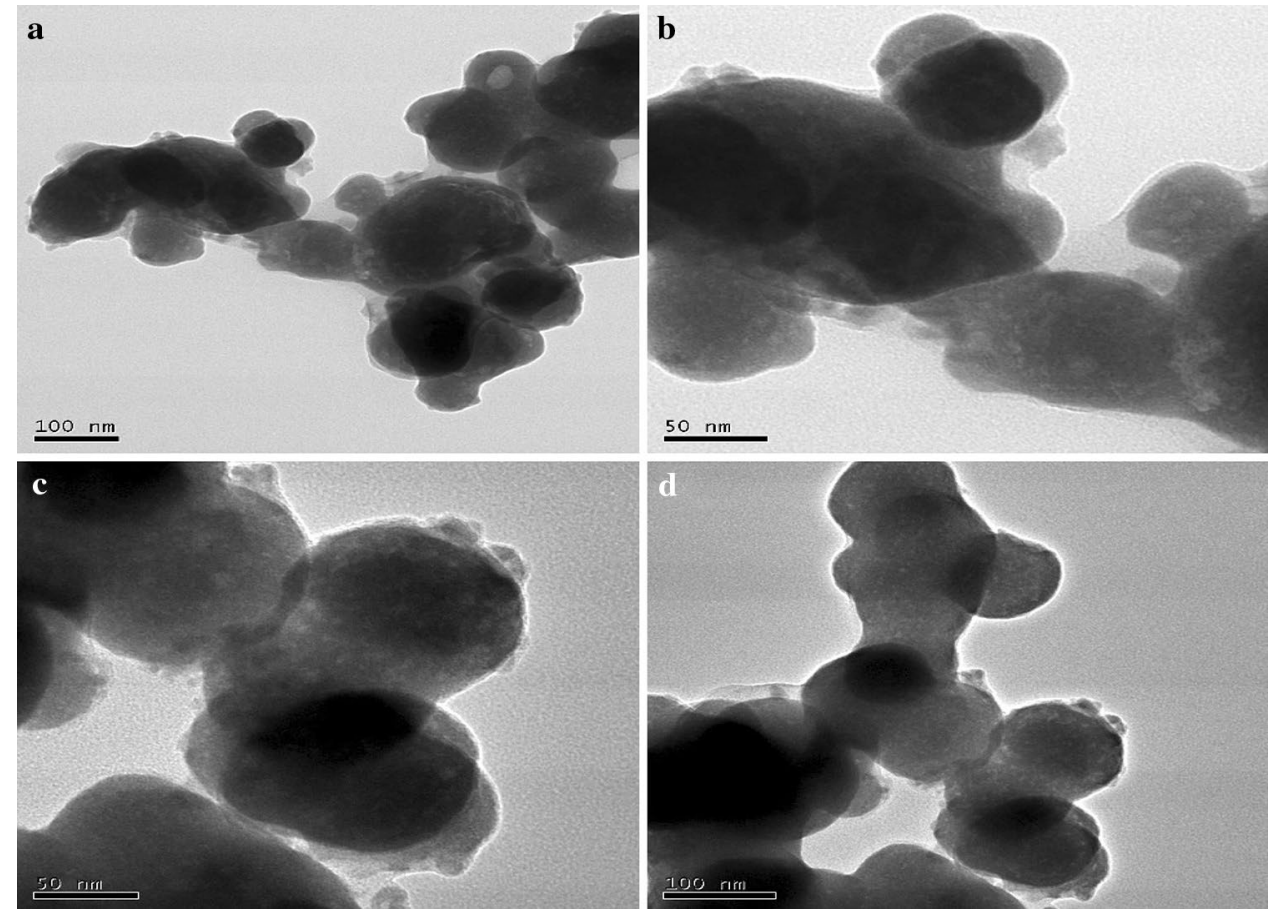

\subsection{FTIR analysis}

The FTIR spectra of SA and PA/SANC was presented in Fig. 2a, b. In Fig. 2 b, peak at $3063 \mathrm{~cm}^{-1}$ showed the $\mathrm{O}-\mathrm{H}$ vibration of water molecule. The peak at $1621 \mathrm{~cm}^{-1}$

\section{SN Applied Sciences}

shifts to $1714 \mathrm{~cm}^{-1}$ was due to $\mathrm{C}=0$ stretching. Peaks at $1481 \mathrm{~cm}^{-1}$ and $755 \mathrm{~cm}^{-1}$ corresponds to C-N stretching and metal oxide linkage. Peaks at $2338 \mathrm{~cm}^{-1}$ and $1192 \mathrm{~cm}^{-1}$ gets disappeared which authorizes the 

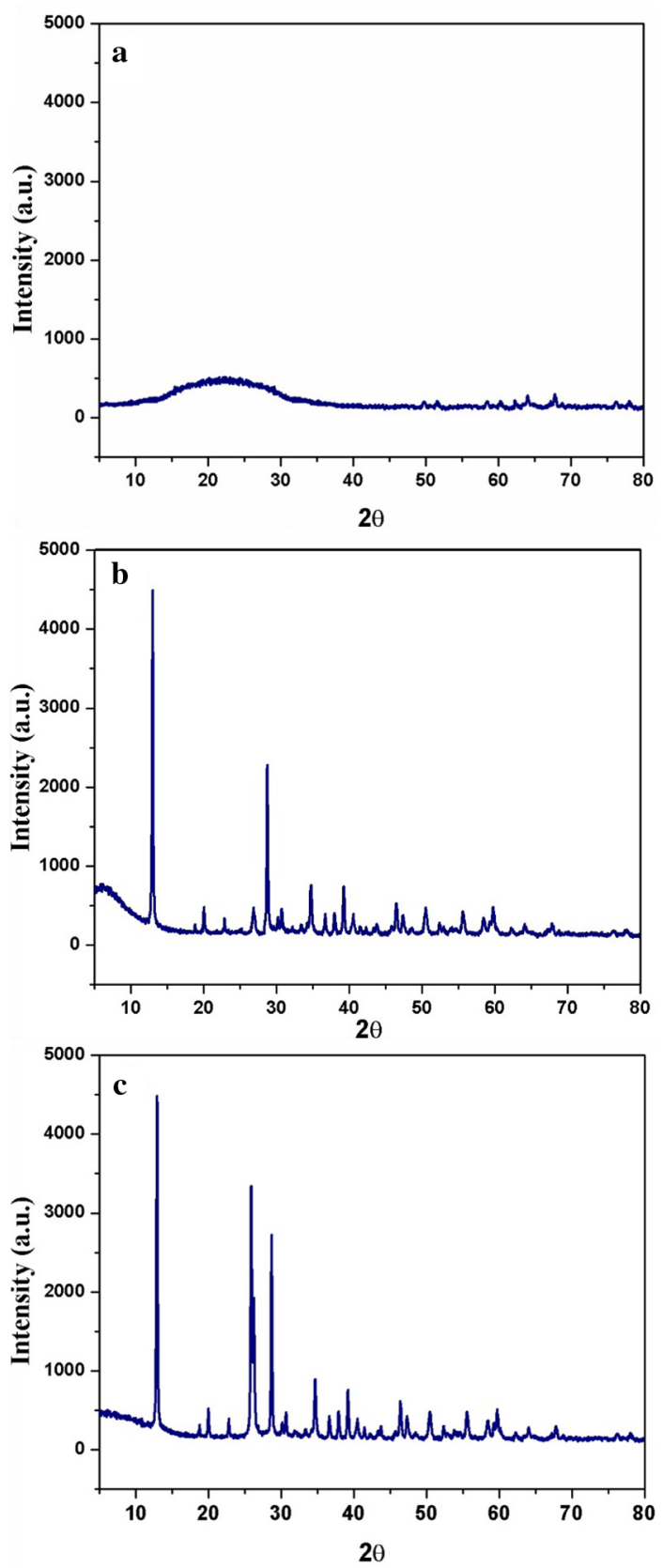

Fig. 6 XRD spectra of a polyacrylamide, b SA, c PA/SANC ion exchanger

significant interaction among polyacrylamide and stannic arsenate ensuing the formation of PA/SANC [46-49].

\subsection{SEM and EDX}

Figure $3 a$, b demonstrates the SEM micrographs of SA with irregular and rough surface. After the binding of organic matrix with inorganic precipitate, entire morphology
Table $2 K_{d}$ values of different metal ions using PA/SANC column in different solvent system

\begin{tabular}{lllll}
\hline S. no. & Metal ions & \multicolumn{3}{l}{$\mathrm{K}_{\mathrm{d}}(\mathrm{mL} / \mathrm{g})$} \\
\cline { 3 - 5 } & \multicolumn{5}{c}{$\begin{array}{l}\text { Distilled } \\
\text { Water }(\mathrm{DW})\end{array}$} & $0.1 \mathrm{~N} \mathrm{HNO}_{3}$ & $0.5 \mathrm{~N} \mathrm{HNO}_{3}$ \\
\hline 1 & $\mathrm{Mg}^{2+}$ & 222.90 & 210.34 & 199.23 \\
2 & $\mathrm{Co}^{2+}$ & 192.66 & 187.24 & 178.22 \\
3 & $\mathrm{Cu}^{2+}$ & 154.66 & 150.50 & 144.44 \\
4 & $\mathrm{Al}^{3+}$ & 111.00 & 100.67 & 91.82 \\
5 & $\mathrm{Ni}^{2+}$ & 98.00 & 95.31 & 88.84 \\
6 & $\mathrm{~Pb}^{2+}$ & 81.00 & 77.67 & 73.22 \\
7 & $\mathrm{Cd}^{2+}$ & 63.33 & 58.66 & 49.99 \\
8 & $\mathrm{Zn}^{2+}$ & 35.78 & 33.33 & 29.38 \\
\hline
\end{tabular}

of PA/SANC was fully transformed in granular surface as shown in Fig. 3c, d. Figure 4 demonstrates EDX spectrum with different intensity peaks for $\mathrm{C}, \mathrm{N}, \mathrm{O}, \mathrm{Cl}, \mathrm{Na}, \mathrm{Sn}$, $\mathrm{Cu}$ and As which confirms the formation of PA/SANC ion exchanger.

\subsection{TEM analysis}

TEM images of PA/SANC at different magnification has been presented in Fig. 5a-d. The darker portion was due to incorporation of inorganic part into polymer matrix of acrylamide. Spherical-shaped morphologies has been formed with interstitial spaces which provide the larger exterior area for sorption of dyes and heavy metals from aqueous system. TEM micrographs reveal that the particle size of PA/SANC was in range $50-100 \mathrm{~nm}$ which confirms that PA/SANC was a nano material.

\subsection{XRD analysis}

Figure 6a-c illustrated the X-ray diffraction pattern of polyacrylamide, SA and PA/SANC respectively. Diffractogram of polyacrylamide shows a broad diffraction hump around $22.8^{0}$ reveling the amorphous nature of polyacrylamide [50]. The sharp diffraction peaks recognized in the diffrectrogram of SA as depicted in Fig. 6b. SANC possesses semi-crystalline nature as concluded from the Fig. $6 \mathrm{c}$. The amendment in the intensities of peaks confirmed the formation of composite ion exchanger. Moreover, the average particle size has been calculated from Scherrer equation as given below and it comes out to be equal to $40 \mathrm{~nm}$ which is in accordance with the TEM results.

$D=\frac{K \lambda}{\beta \cos \theta}$ 
Table 3 Binary separations of metal ions onto the column of PA/SANC ion exchanger column

\begin{tabular}{lcclll}
\hline Binary mixtures & $\begin{array}{l}\text { Amount } \\
\text { loaded } \\
(\mathrm{mg})\end{array}$ & $\begin{array}{l}\text { Amount } \\
\text { found }(\mathrm{mg})\end{array}$ & \% Recovery & Eluent used & $\begin{array}{l}\text { Volume of eluent required } \\
\text { for elution of metal ions }(\mathrm{mL})\end{array}$ \\
\hline $\mathrm{Cu}^{2+}$ & 6.35 & 5.01 & 78.74 & $0.1 \mathrm{NHNO}_{3}$ & 50 \\
$\mathrm{Mg}^{2+}$ & 2.43 & 2.15 & 88.47 & $0.5 \mathrm{NHNO}_{3}$ & 60 \\
$\mathrm{Ni}^{2+}$ & 5.86 & 4.69 & 80.03 & $0.1 \mathrm{~N} \mathrm{HNO}_{3}$ & 50 \\
$\mathrm{Co}^{2+}$ & 5.89 & 5.24 & 88.96 & $0.5 \mathrm{~N} \mathrm{HNO}_{3}$ & 70 \\
$\mathrm{Cd}^{2+}$ & 11.24 & 9.02 & 80.24 & $0.1 \mathrm{NHNO}_{3}$ & 50 \\
$\mathrm{Al}^{3+}$ & 2.69 & 2.33 & 88.25 & $0.5 \mathrm{NHNO}_{3}$ & 60 \\
$\mathrm{Co}^{2+}$ & 5.89 & 4.33 & 73.58 & $0.1 \mathrm{~N} \mathrm{HNO}_{3}$ & 50 \\
$\mathrm{Mg}^{2+}$ & 2.43 & 1.98 & 81.48 & $0.5 \mathrm{~N} \mathrm{HNO}_{3}$ & 70 \\
$\mathrm{Cd}^{2+}$ & 11.24 & 8.76 & 78.21 & $0.1 \mathrm{NHNO}_{3}$ & 50 \\
$\mathrm{Ni}^{2+}$ & 5.86 & 4.88 & 83.25 & $0.5 \mathrm{~N} \mathrm{HNO}_{3}$ & 60 \\
$\mathrm{~Pb}^{2+}$ & 20.72 & 17.3 & 83.49 & $0.1 \mathrm{~N} \mathrm{HNO}_{3}$ & 60 \\
$\mathrm{Co}^{2+}$ & 5.89 & 5.34 & 90.66 & $0.5 \mathrm{NHNO}_{3}$ & 70 \\
$\mathrm{~Pb}^{2+}$ & 20.72 & 16.23 & 78.33 & $0.1 \mathrm{NHNO}_{3}$ & 60 \\
$\mathrm{Mg}^{2+}$ & 2.43 & 2.16 & 88.88 & $0.5 \mathrm{NHNO}_{3}$ & 70 \\
$\mathrm{Zn}^{2+}$ & 6.53 & 4.82 & 73.81 & $0.1 \mathrm{NHNO}_{3}$ & 50 \\
$\mathrm{Cd}^{2+}$ & 11.24 & 9.40 & 83.62 & $0.5 \mathrm{NHNO}_{3}$ & 60 \\
\hline
\end{tabular}

Fig. 7 a \% degradation of SY under solar illumination, $\mathbf{b}$ UV-Vis absorption spectra of SY at different irradiation time, c pseudo-first-order kinetics graph for photodegradation of SY, d Tauc plot of PA/SANC
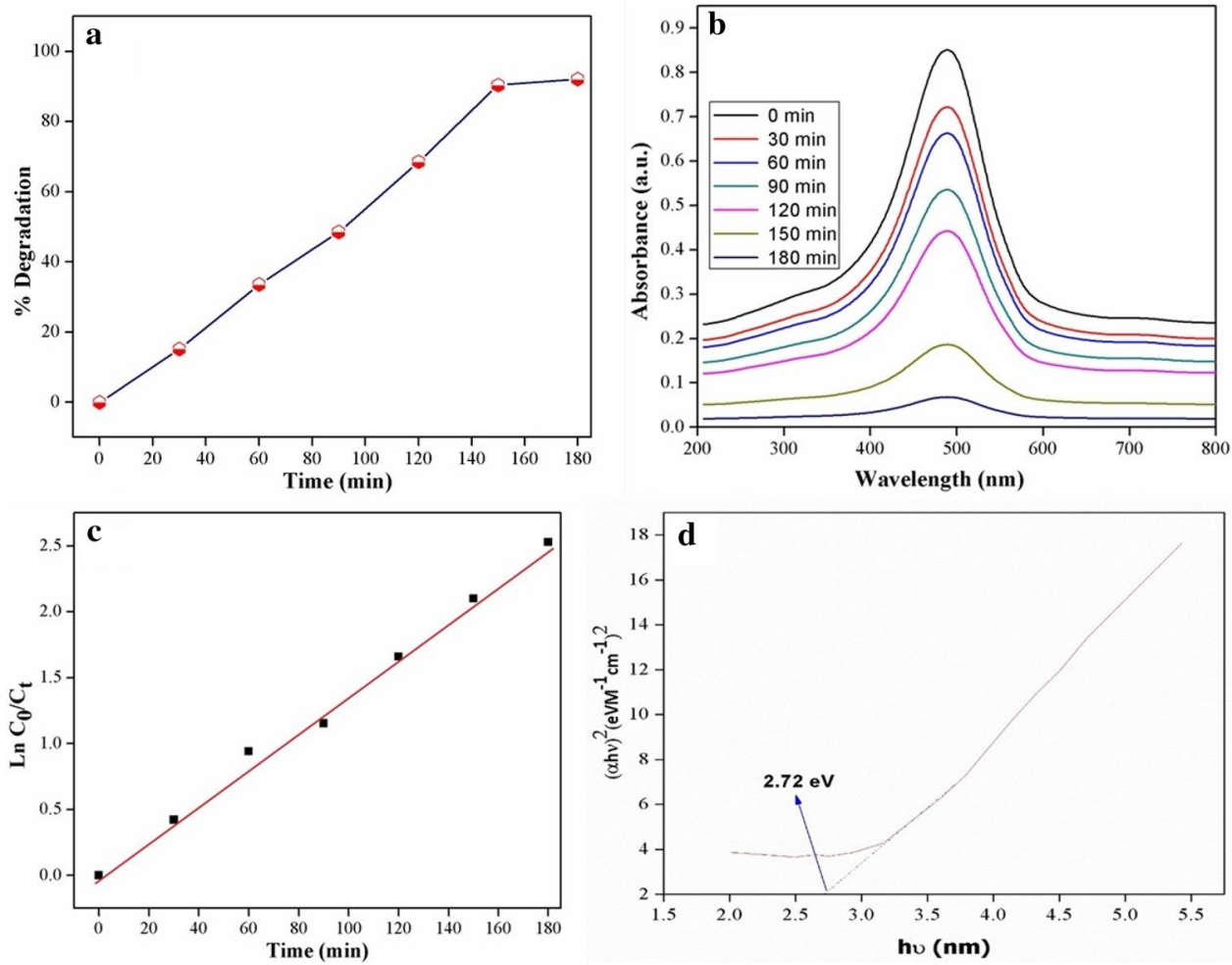

Where $D=$ Crystallite size $(\mathrm{nm}), \lambda=0.15406 \mathrm{~nm}$ (wavelength of the X-Ray sources), $K=0.9$ (Scherrer constant), $\beta=$ FWHM (radian) and $\theta=$ Peak position (radian).

\section{$3.5 K_{d}$ values and binary separations}

Table 2 shows the $K_{d}$ values of different metal ions using PA/SANC column in different solvent system. The 
order of $\mathrm{K}_{\mathrm{d}}$ values were magnesium (222.90) > cobalt (192.66) > copper (154.66) > aluminum (111) > nickel (98) > lead (81) > cadmium (63.33) > zinc (35.78). It has been found that PA/SANC was highly selective for magnesium ions with high distribution coefficient value. It may be due to the appropriate size of $\mathrm{Mg}(\mathrm{II})$ with the pores of matrix and results strong binding of metal cation into the pores [45].

On the basis of distribution coefficient values, binary separations of different metal ions has been accomplished on PA/SANC column as revealed in Table 3. The elution of different metal ions has been determined by metal-ligand stability and elution behavior of PA/SANC ion exchanger. It has been observed that metal ions with smaller values of distribution coefficient were eluted first on the PA/SANC column in contrast to the metal ions with higher value of $\mathrm{K}_{\mathrm{d}}[45]$.

\subsection{Photo-catalytic activity}

The photo-catalytic degradation of sunset yellow was studied onto PA/SANC. Figure 7a illustrate the \% degradation of SY under solar exposure with respect to different time intervals. It has been found that $86.22 \%$ of SY was degraded within $3 \mathrm{~h}$ of solar illumination. When PA/SANC subjected to solar radiation it absorb the light energy and may leads to the photoexcitation due to the presence of tin metal, which ultimately resulted in the formation of $\mathrm{e}^{-}$and $\mathrm{h}^{+}$pairs. It is well known that such type of photoexcitation always lead to the formation of reactive oxygen species (ROS) [51] and responsible for the photodegrading of dye in case of PA/SANC. ROS attacks the dye molecule and distort the conjugation which lead to the degradation. However the time taken for the degradation of dye was $3 \mathrm{~h}$, which may be due to various factor such as charge recombination rate, poor light absorption etc.

Figure $7 \mathrm{~b}$ demonstrated the drop in absorption spectra of SY in diverse intervals of irradiation time. The adsorption curves reduced constantly with different time intervals which specified that PA/SANC degraded dye progressively.

The degradation of SY followed by pseudo firstorder kinetic model was exposed in Fig. 7c. It has been found that SY has higher value of regression coefficient $\left(R^{2}=0.973\right)$ which results $P A / S A N C$ effectively degraded the dye.

Tauc plot of PA/SANC was shown in Fig. 7d and optical band gap was calculated by extrapolating the straight portion of curve between $(a h v)^{2}$ and hv when $a=0$. The band gap was $2.72 \mathrm{eV}$ which illustrate that nanocomposite was semiconductor [52].

\section{Conclusion}

Sol-gel process was employed for the synthesis of PA/ SANC ion exchanger. Different samples of composite was prepared by varying the quantity of organic part. Sample, S-6 with higher value of IEC was explored for further studies. Different characterization techniques like SEM, TEM, FTIR, XRD and EDX has been used to study different aspects of synthesized material. PA/SANC was highly selective for the removal of magnesium ions with higher $\mathrm{K}_{d}$ values. Nanocomposite has been used for the binary separation of metal ions and photodegradation of sunset yellow. PA/SANC has oncoming applications in environmental remediation especially in waste water treatment.

Acknowledgements This research work was supported by the Department of Chemistry, Maharishi Markandeshwar University, Solan. The authors acknowledge Maharishi Markandeshwar University, Solan for providing all basic research facilities to carry out this research work.

\section{Compliance with ethical standards}

Conflict of interest The author declares no conflict of interest.

\section{References}

1. Chowdhary P, Raj A, Bharagava RN (2018) Environmental pollution and health hazards from distillery wastewater and treatment approaches to combat the environmental threats: a review. Chemosphere 194:229-246. https://doi.org/10.1016/j. chemosphere.2017.11.163

2. Gu P, Zhang S, Li X, Wang X, Wen T, Jehan R, Alsaedi A, Hayat $T$ (2018) Recent advances in layered double hydroxide-based nanomaterials for the removal of radionuclides from aqueous solution. Environ Pollut 240:493-505. https://doi.org/10.1016/j. envpol.2018.04.136

3. Vaseashta A, Vaclavikova M, Vaseashta S, Gallios G, Roy P, Pummakarnchana O (2007) Nanostructures in environmental pollution detection, monitoring, and remediation. Sci Technol Adv Mater 8(1-2):47. https://doi.org/10.1016/j.stam.2006.11.003

4. Khreis $\mathrm{H}$, Kelly $\mathrm{C}$, Tate J, Parslow R, Lucas K, Nieuwenhuijsen M (2017) Exposure to traffic-related air pollution and risk of development of childhood asthma: a systematic review and metaanalysis. Environ Int 100:1-31. https://doi.org/10.1016/j.envin t.2016.11.012

5. Rahman FA, Aziz MM, Saidur R, Bakar WA, Hainin MR, Putrajaya R, Hassan NA (2017) Pollution to solution: capture and sequestration of carbon dioxide $\left(\mathrm{CO}_{2}\right)$ and its utilization as a renewable energy source for a sustainable future. Renew Sustain Energy Rev 71:112-126. https://doi.org/10.1016/j.rser.2017.01.011

6. Burakov $A E$, Galunin EV, Burakova IV, Kucherova AE, Agarwal S, Tkachev AG, Gupta VK (2018) Adsorption of heavy metals on conventional and nanostructured materials for wastewater treatment purposes: a review. Ecotoxicol Environ Saf 148:702712. https://doi.org/10.1016/j.ecoenv.2017.11.034 
7. Thakur M, Pathania D, Sharma G, Naushad M, Bhatnagar A, Khan MR (2018) Synthesis, characterization and environmental applications of a new bio-composite gelatin-Zr(IV) phosphate. J Polym Environ 26(4):1415-1424. https://doi. org/10.1007/s10924-017-1043-0

8. Pathania D, Thakur M, Puri V, Jasrotia S (2018) Fabrication of electrically conductive membrane electrode of gelatin-tin(IV) phosphate nanocomposite for the detection of cobalt(II) ions. Adv Powder Technol 29(4):915-924. https://doi.org/10.1016/j. apt.2018.01.009

9. Pathania D, Thakur M, Sharma G, Mishra AK (2018) Tin(IV) phosphate/poly(gelatin-cl-alginate) nanocomposite: photocatalysis and fabrication of potentiometric sensor for $\mathrm{Pb}(\mathrm{II})$. Mater Today Commun 14:282-293. https://doi.org/10.1016/j.mtcom m.2018.01.005

10. Tsoumachidou S, Valari M, Poulios I (2018) Photocatalytic oxidation of psychoactive drug Duloxetine: degradation kinetics, inorganic ions and phytotoxicity evaluation. Appl Chem Eng. https://doi.org/10.24294/ace.v0i0.509

11. Byrne C, Subramanian G, Pillai SC (2018) Recent advances in photocatalysis for environmental applications. J Environ Chem Eng 6(3):3531-3555. https://doi.org/10.1016/j.jece.2017.07.080

12. Wang W, Tadé MO, Shao Z (2018) Nitrogen-doped simple and complex oxides for photocatalysis: a review. Prog Mater Sci 92:33-63. https://doi.org/10.1016/j.pmatsci.2017.09.002

13. Han M, Zhu S, Lu S, Song Y, Feng T, Tao S et al (2018) Recent progress on the photocatalysis of carbon dots: classification, mechanism and applications. Nano Today 19:201-218. https:// doi.org/10.1016/j.nantod.2018.02.008

14. Zhou C, Lai C, Zhang C, Zeng G, Huang D et al (2018) Semiconductor/boron nitride composites: synthesis, properties, and photocatalysis applications. Appl Catal B. https://doi. org/10.1016/j.apcatb.2018.07.011

15. Prakash J, Sun S, Swart HC, Gupta RK (2018) Noble metals-TiO, nanocomposites: from fundamental mechanisms to photocatalysis, surface enhanced Raman scattering and antibacterial applications. Appl Mater Today 11:82-135. https://doi.org/10.1016/j. apmt.2018.02.002

16. Fu F, Wang Q (2011) Removal of heavy metal ions from wastewaters: a review. J Environ Econ Manag 92(3):407-418. https:// doi.org/10.1016/j.jenvman.2010.11.011

17. Hua M, Zhang S, Pan B, Zhang W, Lv L, Zhang Q (2012) Heavy metal removal from water/wastewater by nanosized metal oxides: a review. J Hazard Mater 211:317-331. https://doi. org/10.1016/j.jhazmat.2011.10.016

18. Ngah WW, Hanafiah MA (2008) Removal of heavy metal ions from wastewater by chemically modified plant wastes as adsorbents: a review. Bioresour Technol 99(10):3935-3948. https:// doi.org/10.1016/j.biortech.2007.06.011

19. Budnyak TM, Aminzadeh S, Pylypchuk IV, Sternik D, Tertykh VA, Lindström ME et al (2018) Methylene Blue dye sorption by hybrid materials from technical lignins. J Environ Chem Eng 6(4):4997-5007. https://doi.org/10.1016/j.jece.2018.07.041

20. Budnyak TM, Gładysz-Płaska A, Strizhak AV, Sternik D, Komarov IV, Majdan M et al (2018) Imidazole-2yl-phosphonic acid derivative grafted onto mesoporous silica surface as a novel highly effective sorbent for uranium(VI) ion extraction. Appl Mater Interfaces 10(7):6681-6693. https://doi.org/10.1021/acsam i.7b17594

21. Sharma G, Thakur B, Naushad M, Ala'a H, Kumar A, Sillanpaa M, Mola GT (2017) Fabrication and characterization of sodium dodecyl sulphate@ ironsilicophosphate nanocomposite: ion exchange properties and selectivity for binary metal ions. Mater Chem Phys 193:129-139. https://doi.org/10.1016/j.matchemphy s.2017.02.010

SN Applied Sciences

SPRINGER NATURE journal
22. Pathania D, Sharma G, Thakur R (2015) Pectin@ zirconium (IV) silicophosphate nanocomposite ion exchanger: photo catalysis, heavy metal separation and antibacterial activity. Chem Eng J 267:235-244. https://doi.org/10.1016/j.cej.2015.01.004

23. Awual MR (2017) Novel nanocomposite materials for efficient and selective mercury ions capturing from wastewater. Chem Eng J 307:456-465. https://doi.org/10.1016/j.cej.2016.08.108

24. Sharma G, Naushad M, Ala'a H, Kumar A, Khan MR, Kalia S, Bala M, Sharma A (2017) Fabrication and characterization of chitosan-crosslinked-poly(alginic acid) nanohydrogel for adsorptive removal of $\mathrm{Cr}(\mathrm{VI})$ metal ion from aqueous medium. Int J Biol Macromol 95:484-493. https://doi.org/10.1016/j.ijbio mac.2016.11.072

25. Sarkar S, Chatterjee PK, Cumbal LH, Sen Gupta AK (2011) Hybrid ion exchanger supported nanocomposites: sorption and sensing for environmental applications. Chem Eng J 166(3):923-931. https://doi.org/10.1016/j.cej.2010.11.075

26. Sharma G, Pathania D, Naushad M, Kothiyal NC (2014) Fabrication, characterization and antimicrobial activity of polyaniline Th(IV) tungstomolybdophosphate nanocomposite material: efficient removal of toxic metal ions from water. Chem Eng J 251:413-421. https://doi.org/10.1016/j.cej.2014.04.074

27. Gupta VK, Agarwal S, Tyagi I, Pathania D, Rathore BS, Sharma G (2015) Synthesis, characterization and analytical application of cellulose acetate-tin(IV) molybdate nanocomposite ion exchanger: binary separation of heavy metal ions and antimicrobial activity. lonics 21(7):2069-2078. https://doi.org/10.1007/ s11581-015-1368-4

28. Khan A, Asiri AM, Rub MA, Azum N, Khan AA, Khan SB, Rahman MM, Khan I (2013) Synthesis, characterization of silver nanoparticle embedded polyaniline tungstophosphate-nanocomposite cation exchanger and its application for heavy metal selective membrane. Compos B Eng 45(1):1486-1492. https://doi. org/10.1016/j.compositesb.2012.09.023

29. Pathania D, Thakur M, Mishra AK (2017) Alginate-Zr(IV) phosphate nanocomposite ion exchanger: binary separation of heavy metals, photocatalysis and antimicrobial activity. J Alloys Compd 701:153-162. https://doi.org/10.1016/j.jallc om.2017.01.112

30. Bushra R, Naushad M, Adnan R, ALOthman ZA, Rafatullah $M$ (2011) Polyaniline supported nanocomposite cation exchanger: synthesis, characterization and applications for the efficient removal of $\mathrm{Pb}^{2+}$ ion from aqueous medium. Colloids Surf B Biointerfaces 87(1):122-128. https://doi.org/10.1016/j. jiec.2014.05.022

31. Nabi SA, Shahadat M, Bushra R, Shalla AH, Azam A (2017) Synthesis and characterization of nano-composite ion-exchanger; its adsorption behavior. J Power Sources 342:1-8. https://doi. org/10.1016/j.colsurfb.2011.05.011

32. Zhang L, Huang D, Hu N, Yang C, Li M, Wei H, Yang Z, Su Y, Zhang $Y$ (2016) Three-dimensional structures of graphene/polyaniline hybrid films constructed by steamed water for high-performance supercapacitors. Trends Anal Chem 85:47-56. https:// doi.org/10.1016/j.jpowsour.2016.11.068

33. Mousavi M, Habibi-Yangjeh A, Pouran SR (2018) Review on magnetically separable graphitic carbon nitride-based nanocomposites as promising visible-light-driven photocatalysts. J Mater Sci Mater Electron 29(3):1719-1747. https://doi.org/10.1007/ s10854-017-8166-x

34. Sherlala Al, Raman AA, Bello MM, Asghar A (2018) A review of the applications of organo-functionalized magnetic graphene oxide nanocomposites for heavy metal adsorption. Chemosphere 193:1004-1017. https://doi.org/10.1016/j.chemospher e.2017.11.093

35. Guo Y, Xu G, Yang X, Ruan K, Ma T et al (2018) Significantly enhanced and precisely modeled thermal conductivity in 
polyimide nanocomposites with chemically modified graphene via in situ polymerization and electrospinning-hot press technology. J Mater Chem C 6(12):3004-3015. https://doi. org/10.1039/C8TC00452H

36. Budnyak T, Aminzadeh S, Pylypchuk I, Riazanova A, Tertykh V, Lindström M, Sevastyanova O (2018) Peculiarities of synthesis and properties of lignin-silica nanocomposites prepared by solgel method. Nanomaterials 8(11):950. https://doi.org/10.3390/ nano8110950

37. Kołodyńska D, Budnyak TM, Hubicki Z, Tertykh VA (2017) Sol-gel derived organic-inorganic hybrid ceramic materials for heavy metal removal. In: Mishra AK (ed) Sol-gel based nanoceramic materials: preparation, properties and applications. Springer, Cham, pp 253-274. https://doi.org/10.1007/978-3-319-49512 -5_9

38. Pathania D, Thakur M, Sharma A, Agarwal S, Gupta VK (2017) Synthesis of lactic acid-Zr(IV) phosphate nanocomposite ion exchanger for green remediation. Ionics 23(3):699-706. https ://doi.org/10.1007/s11581-016-1858-z

39. Thakur M, Pathania D (2018) Fabrication of gelatin-Zr(IV) phosphate and alginate-Zr(IV) phosphate nanocomposite based ion selective membrane electrode. In: Nano hybrids and composites. Trans Tech Publications, pp 108-120. https://doi. org/10.4028/www.scientific.net/NHC.20.108

40. Pathania D, Agarwal S, Gupta VK, Thakur M, Alharbi NS (2018) Zirconium(IV) phosphate/poly(gelatin-cl-alginate) nanocomposite as ion exchanger and $\mathrm{Al}^{3+}$ potentiometric sensor. Int J Electrochem Sci 13(1):994-1012. https://doi.org/10.20964 /2018.01.80

41. Naushad M, Sharma G, Kumar A, Sharma S, Ghfar AA, Bhatnagar A, Stadler FJ, Khan MR (2018) Efficient removal of toxic phosphate anions from aqueous environment using pectin based quaternary amino anion exchanger. Int J Biol Macromol 106:1. https://doi.org/10.1016/j.ijbiomac.2017.07.169

42. Naushad M, ALOthman ZA (2015) Separation of toxic $\mathrm{Pb}^{2+}$ metal from aqueous solution using strongly acidic cation-exchange resin: analytical applications for the removal of metal ions from pharmaceutical formulation. Desalin Water Treat 53(8):21582166. https://doi.org/10.1080/19443994.2013.862744

43. Abdelaal MY, Mohamed RM (2013) Novel Pd/TiO 2 nanocomposite prepared by modified sol-gel method for photocatalytic degradation of methylene blue dye under visible light irradiation. J Alloys Compd 576:201-207. https://doi.org/10.1016/j.jallc om.2013.04.112

44. Saravanan R, Sacari E, Gracia F, Khan MM, Mosquera E, Gupta VK (2016) Conducting PANI stimulated ZnO system for visible light photocatalytic degradation of coloured dyes. J Mol Liq 221:1029-1033. https://doi.org/10.1016/j.molliq.2016.06.074

45. Sharma G, Pathania D, Naushad M (2014) Preparation, characterization and antimicrobial activity of biopolymer based nanocomposite ion exchanger pectin zirconium (IV) selenotungstophosphate: application for removal of toxic metals. J Ind Eng Chem 20(6):4482-4490. https://doi.org/10.1016/j. jiec.2014.02.020

46. Yan J, Wei T, Shao B, Fan Z, Qian W, Zhang M et al (2010) Preparation of a graphene nanosheet/polyaniline composite with high specific capacitance. Carbon 48(2):487-493. https://doi. org/10.1016/j.carbon.2009.09.066

47. Jang SH, Han MG, Im SS (2000) Preparation and characterization of conductive polyaniline/silica hybrid composites prepared by sol-gel process. Synth Met 110(1):17-23. https://doi. org/10.1016/S0379-6779(99)00176-9

48. Cai Z, Li L, Ren J, Qiu L, Lin H, Peng H (2013) Flexible, weavable and efficient microsupercapacitor wires based on polyaniline composite fibers incorporated with aligned carbon nanotubes. J Mater Chem A 1(2):258-261. https://doi.org/10.1039/C2TA0 0274D

49. Smitha S, Mukundan P, Pillai PK, Warrier KG (2007) Silica-gelatin bio-hybrid and transparent nano-coatings through sol-gel technique. Mater Chem Phys 103(2-3):318-322. https://doi. org/10.1016/j.matchemphys.2007.02.068

50. Shen J, Yan B, Li T, Long Y, Li N, Ye M (2012) Study on grapheneoxide based polyacrylamide composite hydrogels. Compos $A$ Appl Sci Manuf 43(9):1476-1481. https://doi.org/10.1016/j. compositesa.2012.04.006

51. Kumar A, Kumar A, Sharma G, Ala'a $H$, Naushad M, Ghfar AA et al (2018) Biochar-templated g- $\mathrm{C}_{3} \mathrm{~N}_{4} / \mathrm{Bi}_{2} \mathrm{O}_{2} \mathrm{CO}_{3} / \mathrm{CoFe}_{2} \mathrm{O}_{4}$ nanoassembly for visible and solar assisted photo-degradation of paraquat, nitrophenol reduction and $\mathrm{CO}_{2}$ conversion. Chem Eng J 339:393-410. https://doi.org/10.1016/j.cej.2018.01.105

52. Pathania D, Thakur M, Jasrotia S, Agarwal S, Gupta VK (2017) Gelatin-zirconium dioxide nanocomposite as a Ni(II) selective potentiometric sensor: heavy metal separation and photocatalysis. Int J Electrochem Sci 12(9):8477-8494. https://doi. org/10.20964/2017.09.49

Publisher's Note Springer Nature remains neutral with regard to jurisdictional claims in published maps and institutional affiliations. 